\title{
Catharsis: een vergeten functie van financiële verantwoording*
}

\author{
Sjoerd Keulen \& Ronald Kroeze
}

\section{Introductie}

In het kielzog van de opmars van New Public Management zijn in verschillende landen, waaronder Nederland, prestatiebegrotingen geïntroduceerd. Prestatiebegrotingen zijn gebaseerd op prestatiegegevens in de veronderstelling dat bestuurders en politici hiermee meer controle krijgen op budgetten en op de doelmatigheid van het beleid (Mauro, Cinquini, \& Grossi, 2017). Daarnaast zou hiermee het verantwoordingsproces worden versterkt, een essentieel onderdeel van democratie (Clark, Menifield, \& Stewart, 2018). Volgens Bovens (2007) is verantwoording te definiëren als een sociale relatie waarin een actor zich verplicht voelt om zijn optreden uit te leggen en te rechtvaardigen tegenover een belangrijke ander.

Tegelijkertijd is er veel kritiek op het gebruik van prestatiegegevens door politici; zij zouden prestatiegegevens nauwelijks gebruiken in de dagelijkse praktijk of slechts om incidenteel op een emotionele manier op mismanagement te wijzen, wat weer de vraag oproept of de aanname wel klopt dat meer informatie over overheidsprestaties en overheidsfinanciën leidt tot meer controle en betere verantwoording (Heinrich, 2002; Demaj \& Summermatter, 2012). In Nederland wordt over Verantwoordingsdag - een voorbeeld van een debat over prestatiegegevens - vaak dit type kritiek geuit (Schillemans \& Bovens, 2009; Keulen, 2019).

Wij stellen voor op een andere manier te kijken naar de relatie tussen verantwoording, prestatiegegevens en emoties, namelijk met behulp van het begrip catharsis (zie ook Dubnick, 2005). Catharsis is het gebruik van sterke emoties als zuiverings- of reinigingsproces dat resulteert in vernieuwing, herstel en verzoening. Bovens (2007) beschrijft catharsis als een van de vijf functies van publieke verantwoording; toch is het concept nooit in de bestuurskunde onderzocht. Door catharsis in een langere parlementaire geschiedenis te plaatsen valt op dat politici veelvuldig in sterk emotionele bewoordingen oordelen over beleid en financiële gegevens met als doel te begrijpen, reinigen en verbeteren. Prestatiegegevens worden dus niet genegeerd, maar anders gebruikt dan veel literatuur stelt (zie ook Dubnick, 2005, p. 403). Dit artikel is een aanzet om de uiting en opmars van emoties niet zozeer als 'achteruitgang' van het openbaar bestuur te zien, maar te begrijpen hoe ze (kunnen) bijdragen aan een beter openbaar bestuur. De aandacht voor catharsis is mede geïnspireerd door hernieuwde aandacht voor moraliteit in

* Dr. S.J. Keulen is universitair docent aan de Erasmus Universiteit Rotterdam.

Dr. D.B.R. Kroeze is universitair docent aan de Vrije Universiteit te Amsterdam. 
de bestuurskunde en politieke geschiedenis alsook door geesteswetenschappelijk onderzoek naar de opmars van emoties in de politiek en het financieel-economische domein (Frevert, 2019a; 2019b) en past zo goed binnen de context-gebonden en intersubjectieve perspectieven van positieve bestuurskunde.

We laten zien dat succesvolle verantwoording meer is en moet zijn dan strakke 'rationele' debatten over de precieze cijfers (vergelijk Schillemans \& Bovens, 2009). Dit artikel laat zien dat momenten van overheidsfalen dankzij catharsis kunnen worden gebruikt voor verbetering en succesvol overheidsbeleid. Nationale trauma's als 'Srebrenica', de Bijlmerramp en financiële schandalen als Vestia of RSV kunnen worden verwerkt door emoties. Verbetering begint bij catharsis omdat catharsis leidt tot zowel een nieuwe start als leren.

Wij werken ons argument als volgt uit. Allereerst bespreken we de oorsprong van catharsis en de relatie tussen catharsis en verantwoording. Daarna laten we op basis van de Nederlandse parlementaire debatten zien hoe catharsis onderzocht kan worden. We laten zien dat er een historische toename is van cathartische emoties en dat deze veelvuldig worden ingezet tijdens financiële debatten, vooral tijdens begrotingsdebatten. Om empirisch te laten zien hoe catharsis zich in dergelijke debatten manifesteert, sluiten we af met twee voorbeelden.

\section{De oorsprong van catharsis}

Catharsis is het oud-Griekse woord voor zuivering of reiniging. Aristoteles en Plato introduceerden catharsis als een metafoor voor een proces van zuivering of van reiniging op basis van sterke emoties dat resulteert in vernieuwing, herstel en verzoening. Catharsis werd in de oud-Griekse wereld gebruikt met betrekking tot onderwerpen zo divers als onderwijs, geneeskunde, religie en theater.

De filosofe Martha Nussbaum (2001, p. 281) heeft aangetoond hoe Plato in zijn Republiek emoties, zoals medelijden of angst, zag als krachtige belemmering om tot rationele besluitvorming te komen. Om terug te keren tot rationeel overleg was volgens Plato een vorm van catharsis, "het proces van schoonmaken of opruimen door het verwijderen van een obstakel', nodig. In zijn latere werk Wetten ontwikkelde Plato zijn concept van catharsis verder naar het voorbeeld van de medische zuivering. Plato legde uit dat genezing pas kan beginnen na een fase van tijdelijke stoornis en zwakte. Met andere woorden, de dingen moeten eerst erger worden gemaakt voordat een 'betere nieuwe orde' kan worden vastgesteld (Belfiore, 1986). Nussbaum liet ook zien dat Plato's leerling Aristoteles in zijn Poëtica catharsis gebruikte als een sleutelconcept waarin emoties, inzicht verwerven en leren werden gecombineerd. Aristoteles, die het voorbeeld van het toneel hanteerde, voerde aan dat het publiek catharsis kon ondergaan door emoties op het toneel aan te voelen en daarna te leren van deze emoties (Nussbaum, 2001). Solbakk (2006) benadrukte daarom dat catharsis ook een therapeutische functie had. 
Kortom, catharsis heeft twee essentiële en gerelateerde componenten: een emotionele, waarbij het gaat om het uiten van emoties ten behoeve van (emotionele) verwerking, en een cognitieve, waarbij het gaat om het verkrijgen van inzicht om een verbetering te realiseren (Powell, 2007).

\section{Verantwoording en catharsis}

Bovens (2007) legde voor het eerst een verband tussen catharsis en moderne verantwoording. Hij betoogde dat publieke verantwoording drie functies heeft: het versterken van (1) democratische controle, (2) de integriteit van het bestuur en (3) het lerend vermogen. Deze drie functies samen vormen de vierde en vijfde functie, die meer indirect zijn, respectievelijk die van (4) behoud en verbetering van legitimiteit en (5) catharsis - een proces van (morele) reiniging en lering dat in gang wordt gezet door het uiten van sterke emoties. Het belang van deze laatste functie wordt onderschreven door Dubnick (2005) en het sluit aan bij pleidooien van politicologen en historici om emoties te begrijpen als voorwaarde voor de rede en rationele democratische besluitvorming (Marcus, 2010; Frevert, 2019a). Zij wijzen er ook op dat zonder deze emotie een belangrijke bron voor revitalisatie van de democratie ontbreekt.

De functiebenadering van Bovens bleef niet onbesproken. Met name op de indirecte functies legitimiteit en catharsis ontstond kritiek, omdat ze geen inherente functie van verantwoording zouden zijn, en criticasters meenden dat functies neutraal dienen te zijn en niet positief of negatief (Willems \& Van Dooren, 2012, p. 1023). De indeling die Willems en Van Dooren zelf presenteren, onderscheidt de aspecten 'answerability' en 'managing expectations'. Answerability draait om drie zaken: degene die verantwoording aflegt, behoort tot een ander orgaan. Dat doet hij door sociale interactie, waarbij, als derde kenmerk, de relatie ongelijk is vanwege de morele autoriteit van de degene die verantwoording vraagt (Willems \& Van Dooren, 2011; 2012). Ook in deze classificatie is catharsis naar ons idee goed in te passen omdat catharsis immers draait om morele emoties en morele classificaties.

Bovens reageerde op de functiekritiek door een nieuw analytisch onderscheid van verantwoording te presenteren: de Atlantische normatieve traditie van verantwoording als deugd en verantwoording als mechanisme, de beschrijving van de sociale interacties in het verantwoordingsproces (Bovens, 2010). Deze dichotomie is echter niet absoluut, in de werkelijkheid is er veel overlap tussen beide gebruiken (Willems \& Van Dooren, 2011). Dat blijkt wel voor het geval van catharsis dat Bovens (2010, p. 954) in zijn tweedeling classificeert als mechanisme en als inherent onderdeel van verantwoording, maar gezien het morele oordeel kan het naar ons idee net zo goed als een deugd worden omschreven.

Catharsis is dus een vorm van zuivering door emotionele oordeelsvorming en als een element van verantwoording creëert het een band die verzekert dat individuen en instellingen moreel verantwoordelijk zijn voor hun handelingen. Cathar- 
sis in de politiek neemt de vorm aan van moreel oordelen en is een manier om 'politieke moraliteit' (opnieuw) te bepalen. Dit sluit aan bij historisch onderzoek dat aantoont dat politieke debatten over en parlementaire onderzoeken naar misbruik van publieke macht en middelen niet alleen dienen om feiten vast te stellen, maar ook om getuigen te beoordelen, vast te stellen wat goed en slecht bestuur is en verbeteringen te kunnen doorvoeren (Kroeze, 2014). Daarom is de functie van catharsis niet in de eerste plaats het controleren van feiten of het vaststellen van strafbare feiten volgens het (straf)recht, maar een politiek proces van moreel (ver)oordelen om vast te stellen wat er fout ging en hoe het (in de toekomst) hoort te gaan. Juist het emotionele oordeel dient om de band met en het vertrouwen van het publiek in het zelfreinigende vermogen van instellingen te herstellen.

Van de socioloog Émile Durkheim kunnen we leren hoe dit mechanisme werkt. Het delen van emoties helpt bij het creëren van een gevoel van verbondenheid dat op zijn beurt sociale integratie bevordert en gemeenschappelijke overtuigingen versterkt. Dientengevolge ervaren individuen een hernieuwd vertrouwen, krijgen ze kracht en worden ze zelfverzekerder (Durkheim, 1915). Het gezamenlijk uiten en sociaal delen van emoties is dus een nuttig hulpmiddel voor politici om de aandacht te vestigen op een bepaald onderwerp, gevoelens van verbondenheid tussen kiezer en politicus te creëren en het vertrouwen in het democratisch systeem te versterken of herstellen (Ankersmit \& Te Velde, 2004; Frevert, 2019a).

Ten slotte speelt catharsis nog een andere rol: het helpt om het verleden te verwerken. Idealiter wordt via het louterende proces van morele oordeelsvorming de waarheid blootgelegd, en door verantwoordelijkheid te nemen en excuses aan te bieden kan een nieuwe start worden gemaakt (Ignatieff, 1996). Dit geldt bijvoorbeeld voor parlementaire enquêtes. Vanaf de introductie van de parlementaire enquête in Nederland in 1848/1850 is er gewezen op de tweeledige rol van enquêtes: enerzijds is het een instrument om extra informatie te vergaren over een deelterrein van het openbaar bestuur, anderzijds is het een manier om over de politiek te oordelen, over wat fout ging, om tot beter bestuur te komen en vertrouwen te herstellen (Kroeze, 2013). Ook uit de memorie van toelichting van de laatste wijziging van de Wet op de parlementaire enquête wordt dat duidelijk: 'Goed uitgevoerd enquêteonderzoek draagt bij aan het vertrouwen in de democratie. Het hoogste democratische orgaan onderzoekt een belangrijke kwestie uitputtend. Emoties of maatschappelijke onrust rond een gebeurtenis of een probleem blijken beter te kunnen worden verwerkt als alle informatie is verzameld en beoordeeld en de Kamer op grond daarvan in openbaarheid haar conclusies trekt' (Kamerstukken II 2005/06, 30 415, nr. 3, p. 7).

Ook juristen hebben erop gewezen dat parlementair onderzoek zoals enquêtes niet een zoektocht zijn naar de objectieve waarheid, maar dat dit altijd het politieke karakter van controle en sturing heeft (Kummeling, 2007). Daarmee zijn enquêtes bovenal een vorm van verantwoording. Ook bestuurskundigen hebben opgemerkt dat sinds de Tweede Wereldoorlog de emotionele en reinigende aspecten van verantwoording een belangrijk onderdeel van enquêtes zijn geworden 
Tabel 1 Operationalisatie van cathartische emoties

\begin{tabular}{|c|c|}
\hline $\begin{array}{l}\text { Cathartische emotie (Scheff \& } \\
\text { Bushnell, I984) }\end{array}$ & $\begin{array}{l}\text { Operationalisatie van deze emotie (Van Dale } \\
\text { Synoniemenwoordenboek) }\end{array}$ \\
\hline Verdriet & $\begin{array}{l}\text { verdriet* rouw kommer leed treurigheid droefenis } \\
\text { smart treurnis }\end{array}$ \\
\hline Angst & angst* bangheid huiver vrees \\
\hline Woede & $\begin{array}{l}\text { woede* schand* kwaad boos frenesie furie toorn gram- } \\
\text { schap toorn drift razernij }\end{array}$ \\
\hline Schaamte & schaam* gêne \\
\hline Verveling & verveling verveel \\
\hline Pijn & pijn* lijd* ellende \\
\hline verlies van controle & tranen lach* (Scheff, 2007) \\
\hline Uitputting & uitgeput moeheid inzinking \\
\hline Verwarring & $\begin{array}{l}\text { verwarr* verbijster* ongeloof confusie ontreddering } \\
\text { desoriëntatie }\end{array}$ \\
\hline
\end{tabular}

(Muller, 2002). Omdat enquêtes gaan over grote misstanden en schandalen zijn de emotionele reacties ook sterker en is de catharsis dus heviger.

\section{Cathartische emoties in parlementaire begrotingsdebatten}

Scheff en Bushnell (1984) hebben een theorie van catharsis geformuleerd. Zij betoogden dat catharsis zich als vijf basisemoties uit: 'verdriet', 'angst', 'woede', 'schaamte' en 'verveling'. Hier voegden ze nog vier emoties aan toe die voelbaar zijn na een moment van catharsis. Dat zijn 'pijn', 'verlies van controle', 'uitputting' en 'verwarring'. We hebben onderzocht of deze negen 'cathartische emoties' een rol speelden in verantwoordingsdebatten in het Nederlandse parlement door elk debat van de Nederlandse Tweede Kamer sinds de oprichting in 1815 te analyseren via search.politicalmashup.nl. Daartoe hebben we de cathartische emoties geoperationaliseerd door de synoniemen van deze synoniemen uit het Van Dale synoniemenwoordenboek te gebruiken. De emotie 'verlies van controle' is in de literatuur geoperationaliseerd als lachen of huilen (Scheff, 2007).

De parlementaire debatten in de database politicalmashup zijn voor debatsanalyse verrijkt met metadata waardoor (1) het onderwerp te identificeren is (bijvoorbeeld begroting, beleidsdocument, wet), (2) het domein (bijvoorbeeld financiën, gezondheid, sociale zekerheid) en (3) de partijen die deelnemen aan elk debat. Dit maakt het mogelijk om vast te stellen of emoties een rol spelen in het parlement en, meer precies, om vast te stellen of die emoties (veel) worden gebruikt in het verantwoordingsproces van begrotingen en jaarverslagen. Als dat zo is, wijst dit erop dat debatten over prestatie-informatie het doel dienen om moreel te oordelen over overheidsgedrag om tot verbetering te komen - catharsis. 


\section{Figuur 1 Gebruik van cathartische emoties in alle debatten van de Staten-} Generaal, 1816-2016

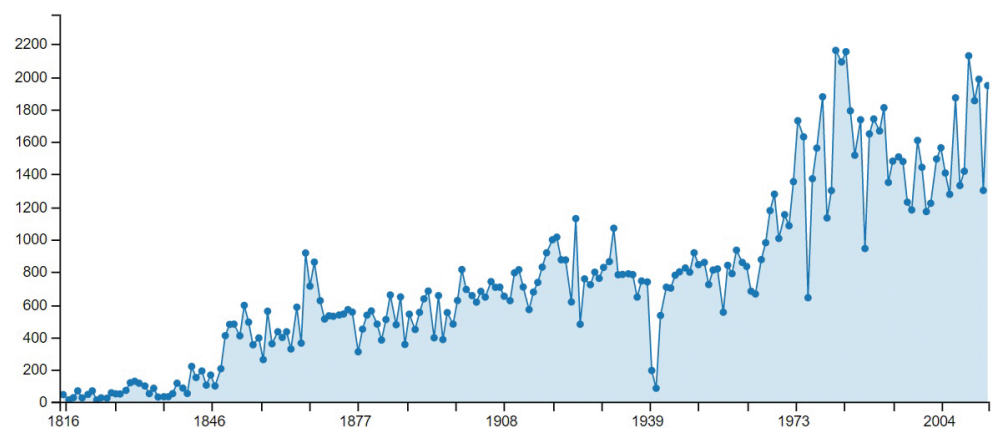

Bron: overgenomen van search.politicalmashup.nl

We vonden opvallende resultaten. De negen cathartische emoties werden 149.398 keer gebruikt in de periode 1815-2016. Wanneer we het gebruik van de emoties door de tijd vergelijken, zien we een eerste piek in 1866, 1867, de jaren waarin de regel van ministeriële verantwoordelijkheid aan het parlement definitief werd geregeld (Wielenga, 2014). Vanaf 1966 tot het begin van de jaren negentig is het gebruik van cathartische emoties toegenomen van 666 maal tot ongeveer 1.500 keer per jaar. Interessant is dat het parlement tijdens de twee grote recente recessies (rond 1982 en rond 2008) het vaakst uiting gaf aan cathartische emoties. Dit zou erop kunnen wijzen dat debatten meer emotioneel zijn in tijden van (financiële) crisis. Dit wordt bevestigd door historica van politieke emoties Ute Frevert, die vaststelde dat tijdens conflicten over economie en financiën heftige morele oordelen en sterke emoties de belangrijkste communicatieve codes waren die werden gebruikt (Frevert, 2019b).

Het verband tussen catharsis en informatie over financiële (wan)prestaties wordt nog duidelijker als we kijken naar de domeinen van de debatten. Financiën (10.339 treffers) steekt ver boven alle andere domeinen uit die in het parlement zijn besproken als we kijken naar het gebruik van cathartische emoties. Op de tweede en derde positie vinden we de andere twee klassieke domeinen van het parlement: bestuur (5.446 treffers) en recht (5.017 treffers). Daarom kunnen we concluderen dat cathartische emoties een grotere rol spelen wanneer het gaat over financiën dan over andere domeinen, inclusief gezondheid (nr. 4), veiligheid (nr. 7) of werk (nr. 10), domeinen die (al wel) als zeer emotioneel worden beschouwd.

Dit sluit aan bij eerdere opmerkingen van Bovens. Volgens Bovens (2007) zijn debatten over jaarlijkse begrotingen en over jaarverslagen de belangrijkste momenten van verantwoording in het democratisch proces. Maar om vast te stellen of catharsis en verantwoording daadwerkelijk verbonden zijn, moet men de debatten over begrotingen en jaarverslagen nader analyseren. Wanneer we kijken naar de onderwerpen van de vijftig debatten waarin cathartische emoties het 
vaakst werden gebruikt, kunnen we vaststellen dat die bijna uitsluitend gingen over begrotingen en jaarverslagen. Van de vijftig debatten waren er slechts drie niet direct verbonden aan het Kamernummer van een begroting of financieel jaarverslag. ${ }^{1}$ Daarmee spelen emoties dus een grote rol in debatten over begrotingen en jaarverslagen en blijkt dat voor financiële verantwoording emoties erg belangrijk zijn. Ook is dit gebruik van emoties niet beperkt tot één partij: tijdens debatten over financiële verantwoording maakten alle partijen nagenoeg evenveel gebruik van cathartische emoties.

\section{Een casestudy van de werking van catharsis}

Om inzicht te geven hoe catharsis werkt in de praktijk van de verantwoording geven wij twee voorbeelden uit parlementaire enquêtes en uit begrotingsdebatten.

Ten eerste de parlementaire enquête woningcorporaties. Deze werd in 2013 ingesteld om het corporatiebeleid te onderzoeken na een serie van misstanden, fraudes en blunders met gemeenschapsgeld. Al tijdens de verhoren merkten de grote Nederlandse dagbladen de rol en het belang van emoties op. De verhoren zorgden voor een gevoel van 'ontluistering' (Trouw, 10 juli 2014) en NRC Handelsblad (22 juni 2014) vond het doorslaan in 'een volkstribunaal waar waarheidsvinding van secundair belang is aan de morele verontwaardiging'. De Volkskrant (30 oktober 2014) meende dat het belangrijkste resultaat [van de enquêtecommissie] is dat er eindelijk een hoofdstuk kan worden gesloten'.

Hoe catharsis er in de praktijk uitziet, werd gedemonstreerd door minister van Binnenlandse Zaken Spies. In haar verhoor ging ze terug naar het gevoel dat ze kreeg toen bleek dat ze niet kon ingrijpen bij Vestia vanwege derivatencontracten met banken die Vestia had getekend.

'Die reactie zal een hele hoop dimensies hebben gehad, maar verbazing, verwondering en boosheid zijn in ieder geval emoties die dan bij je boven komen. Als je geïnformeerd wordt over het dossier en een corporatie van die omvang die puur speculatief en totaal niet met het oog op de volkshuisvesting aan het handelen is geweest en je ook nog eens geconfronteerd wordt met het feit dat er derivaten zijn die zulke giftige clausules bevatten dat daardoor de facto het wettelijk toezicht onmogelijk wordt gemaakt, word je daar buitengewoon chagrijnig van. Je moet jezelf tegelijkertijd goed bewust zijn van alle risico's die die clausules met zich meebrengen. Met de beperkte mogelijkheden die er dan nog zijn, moet je proberen om toch zo goed mogelijk te handelen.' (Kamerstuk II 2014/15, 33 606, nr. 10, p. 1826)

Haar tegenspeler, corporatiedirecteur Staal, toonde ook tal van cathartische emoties. Hij stelde: 
'Er gaat geen dag, geen minuut voorbij of ik moet denken aan de situatie waarin Vestia terecht is gekomen. Dat doet mij meer dan pijn. (...) U mag van mij weten dat het mij verscheurt dat die mensen getroffen worden door de verwikkelingen rondom de derivaten. Dat doet mij meer dan pijn. Ik wilde dat ik de tijd in dat opzicht kon terugdraaien. (...) Spijt is voor mij ... Het doet mij pijn. "Spijt" vind ik een heel moeilijk begrip. Ik wilde dat het anders was gelopen. Ik maak me in die zin ook elke dag zorgen om wat mensen is overkomen.' (Kamerstuk II 2014/15, 33 606, nr. 10, p. 532, 533)

Hoe catharsis een rol kan spelen in het beoordelen van verantwoordingsinformatie, blijkt uit de behandeling van de begroting voor 1985 tijdens de Algemene Beschouwingen van 1984; een debattenreeks waarin in vergelijking met alle andere Kamerdebatten het vaakst cathartische emoties werden gebruikt. Op dat moment was het kabinet-Lubbers I (CDA, VVD) halverwege de rit en, in een periode van economische recessie, begonnen aan forse bezuinigingen, privatiseringen en heroverwegingen. De oppositie onder leiding van PvdA-fractievoorzitter Joop den Uyl stelde zich zeer kritisch op. In de verbatim handelingen van drie dagen Algemene Beschouwingen hebben wij met de geoperationaliseerde cathartische emoties in Atlas.ti 133 keer het gebruik van een van de negen cathartische emoties geconstateerd, waaronder pijn(lijk). ${ }^{2}$ Een voorbeeld.

Den Uyl: 'De afgelopen weken hebben sterk in het teken gestaan van allerlei incidenten, over de positie van de echte meerjarige minima, over werkgelegenheidscijfers, over ministerssalarissen en natuurlijk over de soms driemaal per dag wisselende verklaringen daarover van ministers en van de heren De Vries en Nijpels. In die pijnlijke gebeurtenissen zoek ik geen boze opzet. De vraag is echter waarom ze zo pijnlijk waren. Ze waren zo pijnlijk, Voorzitter, omdat ze duidelijk maakten hoever regering en regeringspartijen vervreemd zijn van de maatschappelijke werkelijkheid. Die trieste werkelijkheid betreft 830.000 werklozen, 750.000 WAO'ers en 634.000 huishoudens, die van één minimuminkomen moeten rondkomen. Het is pijnlijk als Troonrede en Miljoenennota daartegenover het internationale economische herstel naar zich toe rekenen. Die stukken ademen de sfeer van: "het gaat weer beter" en "we zijn op de goede weg”. (...) Met geen woord spreekt de minister van Financiën, die toch voor het totale inkomsten- en uitgavenbeleid van het kabinet verantwoordelijk is, in zijn "Ten geleide" over herstel van werkgelegenheid of over de wijze waarop de pijn van de crisis wordt verdeeld. Elke verwijzing ontbreekt waar het gaat om de wijze, waarop dit kabinet de capaciteiten van dit land en zijn mensen weer denkt aan te spreken. Waar - ik geef nu een oordeel dat ik voorop stel - het kabinet tussen de werkenden en degenen die zijn uitgeschakeld, zou moeten bundelen, speelt dit kabinet groepen uit elkaar.' (Handelingen II, 1984/1985, 289) 
Wat opvalt, is dat de coalitiepartijen zich eveneens van emotionele argumenten bedienen. Dit is des te opvallender omdat de politieke cultuur in die tijd doorgaans als 'zakelijk' en 'no-nonsense' wordt beschouwd, iets wat het kabinet-Lubbers graag omarmde en uitdroeg (Kroeze \& Keulen, 2012). Uit het volgende tekstfragment lijkt CDA-fractievoorzitter De Vries zelfs emotioneel aangeslagen door de kritiek van Den Uyl.

De Vries CDA: 'Dat zijn stuk voor stuk signalen dat wij niet bezig zijn aan deze crisis ten onder te gaan, zoals de heer Den Uyl suggereerde, maar dat wij bezig zijn ons er doorheen te worstelen. Het zijn ook signalen dat dit beleid, hoe pijnlijk ook, toch de juiste koers is. Daarom moeten wij de moed hebben, op deze moeitevolle weg door te gaan. (...) Wij moeten dat beleid voeren onder moeilijke omstandigheden. Perioden van crises zijn immers ook perioden van verwarring en onzekerheid, van tasten en zoeken, van verdachtmakingen en zich bedreigd voelen.' (Handelingen II, 1984/1985, 299, 300)

'Thans worden wij ervan beschuldigd, die verzorgingsstaat te willen ontmantelen, ervan beschuldigd, de zwakkeren zonder enig perspectief in de kou te laten staan en ervan beschuldigd, op weg te zijn naar een twee-klassenmaatschappij waarin het recht van de sterkste weer geldt. Dit doet ons als christen-democraten pijn. Dat steekt ons. Daarmee doet men ons onrecht, want het is niet waar.' (Handelingen II, 1984/1985, 304)

Uit beide voorbeelden blijkt dat cathartische emoties worden ingeroepen tijdens de verantwoording. Bij de voorbeelden van Spies en Den Uyl lijkt dit cognitief doordat ze na de emotie gaan handelen (of dit voorstellen), terwijl bij Staal en De Vries de verwerking (nog) vooropstaat.

\section{Epiloog: discussie en onderzoeksagenda}

We hebben laten zien hoe in Nederlandse debatten over begrotingen en jaarverslagen cathartische emoties veel vaker werden geuit dan in debatten over andere onderwerpen en hebben gepoogd dit te verklaren door het verband tussen catharsis en verantwoording te bespreken. Gezien de geringe omvang van het artikel willen we niet suggereren dat we hiermee definitief hebben bewezen dat de functie van catharsis de belangrijkste verklaring is voor de emotionele vorm die financiële verantwoording vaak aanneemt. We zijn wel van mening dat de rol van emoties en verantwoording een onderontwikkeld onderzoeksthema is.

Dat blijkt al uit de classificering en rubricering van verantwoording. In de besproken definities is er altijd aandacht voor het morele aspect van verantwoording, maar juist dat emotionele aspect blijft in het onderzoek onderbelicht.

Catharsis vervangt daarmee niet de andere functies of rubriceringen van verantwoording; maar het is wel een belangrijk onderbelicht aspect. Juist doordat bij catharsis de emoties zo fel en daarmee goed herkenbaar zijn, kunnen ze onderzocht worden. Te vaak wordt nog over het hoofd gezien dat sterke emotionele 
morele oordelen een functie vervullen en performatief zijn: ze staan aan de basis van nieuw beleid. Juist in tijden van polarisatie spelen emoties een nog grotere rol in de politiek; dat maakt emotie-onderzoek in de huidige tijden zeer relevant.

Dat betekent niet dat elke vorm van catharsis automatisch succesvol is of geaccepteerd wordt door het publiek (Scheff, 2007). Uit de twee voorbeelden lijkt bijvoorbeeld Den Uyl zijn gevoelens meer de vrije loop te laten dan Spies in haar wat technocratischer aandoende antwoord. Naar succesvol catharsis zal meer onderzoek gedaan moeten worden. Dit moet verder worden onderzocht door casestudy's te combineren met kwalitatief onderzoek. Meer systematisch onderzoek, inclusief vergelijkingen tussen landen, kan helpen om vast te stellen of cathartische emoties een rol spelen in andere politieke systemen en op welke verschillende bestuursniveaus. Bovendien kan verder onderzoek bevestigen, zoals onze gegevens suggereren, dat perioden van crises meer emotioneel geladen zijn. Dergelijk onderzoek kan profiteren van inzichten uit de geesteswetenschappen over de rol van emoties en moraliteit rondom financiën in de langere (politieke) geschiedenis. Voor zowel de wetenschappelijke als de bestuurlijke praktijk betekent dit dat catharsis veel serieuzer genomen moet worden als een functie van verantwoording.

Tot slot biedt begrip van catharsis belangrijke inzichten voor de praktijk, van accountant, beleidsmedewerker tot politicus. Allereerst is het nuttig om te weten dat wat gezien wordt als objectief en neutrale cijfers emotionele reacties kan oproepen. Daarnaast dat emoties niet als onbelangrijk en irrationeel weg moeten worden gezet maar een functie hebben: ze geven het publiek en de politiek de mogelijkheid om in het reine te komen met het verleden, hiervan te leren en een nieuwe start te maken.

\section{Literatuur}

Ankersmit, F.R., \& Velde, H. te (Eds.). (2004). Trust: cement of democracy? Leuven: Peeters. Belfiore, E. (1986). Wine and catharsis of the emotions in Plato's laws. The Classical Quarterly, 36(2), 421-437.

Bovens, M. (2007). The concept of public accountability. In E. Ferlie, L.E. Lynn, \& C. Pollitt (Eds.), The Oxford handbook of public management (pp. 182-208). Oxford: Oxford University Press.

Bovens, M. (2010). Two concepts of accountability: Accountability as a virtue and as a mechanism. West European Politics, 33(5), 946-967.

Clark, C., Menifield, C.E., \& Stewart, L.M. (2018). Policy diffusion and performance-based budgeting. International Journal of Public Administration, 41(7), 528-534.

Demaj, L., \& Summermatter, L. (2012). What should we know about politicians' performance information need and use? International Public Management Review, 13(2), $85-111$.

Dubnick, M. (2005). Accountability and the promise of performance: In search of the mechanisms. Public Performance \& Management Review, 28(3), 376-417.

Durkheim, E. (1915). The elementary forms of the religious life: A study in religious sociology. London: Allen \& Unwin. 
Frevert, U. (2019a). Emotional politics . WRR-lezing, Den Haag 24 januari 2019, via www.wrr.nl.

Frevert, U. (Eds.). (2019b). Moral Economies. Gottingen: Vandenbroeck \& Ruprecht.

Heinrich, C.J. (2002). Outcomes-based performance management in the public sector: Implications for government accountability and effectiveness. Public Administration Review, 62(6), 712-725.

Ignatieff, M. (1996). Articles of faith. Index on Censorship, 25(5), 110-122.

Keulen, S. (2019). 20 jaar Verantwoordingsdag: Inzicht voor Kamercommissies: Hoe inhoudsanalyse inzicht geeft in prestatiegegevensgebruik door Kamerleden. Bestuurskunde.

Kroeze, R. (2013). Een kwestie van politieke moraliteit: politieke corruptieschandalen en goed bestuur in Nederland, 1848-1940. Hilversum: Verloren.

Kroeze, R. (2014). Corruptie in de Nederlandse politieke geschiedenis: De functie van debatten over omkoping, belangenverstrengeling en systeemfalen. In C. van Baalen (red.), Jaarboek parlementaire geschiedenis 2014: Het geld regeert (pp. 81-94). Amsterdam: Boom.

Kroeze, R., \& Keulen, S. (2012). Managerpolitiek: Waarom historici oog voor management moeten hebben. BMGN-Low Countries Historical Review, 127(2), 97-112.

Kummeling, H.R.B.M. (2007). Parlementair onderzoek: Op zoek naar de waarheid, met een politiek tintje. In J.Th.J. van den Berg et al. (red.), Het parlement (pp. 69-81). Nijmegen: Wolf Legal Publishers.

Marcus, G.E. (2010). Sentimental citizen: Emotion in democratic politics. University Park: Penn State Press.

Mauro, S.G., Cinquini, L., \& Grossi, G. (2017). Insights into performance-based budgeting in the public sector: A literature review and a research agenda. Public Management Review, 19(7), 911-931.

Muller, E.R., \& Coene, N.J.P. (2002). Parlementair onderzoek in Nederland. Den Haag: Sdu.

Nussbaum, M.C. (2001). The fragility of goodness: Luck and ethics in Greek tragedy and philosophy. Cambridge: Cambridge University Press.

Powell, E. (2007). Catharsis in psychology and beyond: A historic overview. The Primal Psychotherapy, 1.

Scheff, T.J. (2007). Catharsis and other heresies: A theory of emotion. Journal of Social, Evolutionary, and Cultural Psychology, 1(3), 98-113.

Scheff, T.J., \& Bushnell, D.D. (1984). A theory of catharsis. Journal of Research in Personality, 18(2), 238-264.

Schillemans, T., \& Bovens, M. (2009). Publieke verantwoording 2.0: Sober maar scherp. In T. Schillemans \& M. Bovens (red.), Handboek publieke verantwoording (pp. 275-295). Utrecht: Lemma.

Solbakk, J.H. (2006). Catharsis and moral therapy I: a Platonic account. Medicine, Health Care and Philosophy, 9(1), 57-67.

Wielenga, F. (2014). A history of the Netherlands: From the sixteenth century to the present day. London: Bloomsbury.

Willems, T., \& Dooren, W. van. (2011). Lost in diffusion? How collaborative arrangements lead to an accountability paradox. International Review of Administrative Sciences, 77(3), 505-530.

Willems, T., \& Dooren, W. van. (2012). Coming to terms with accountability. Public Management Review, 14(7), 1011-1036. 